\title{
Point of emphasis: retained acupuncture needles after 30 years
}

\author{
Timothy Shun Him Kwok, ${ }^{1}$ Micheal McInnis, ${ }^{2}$ Eric Kaplovitch ${ }^{3}$
}

'Department of Medicine, University of Toronto, Toronto, Ontario, Canada

${ }^{2}$ Division of Cardiothoracic Imaging, Joint Department of Medical Imaging, University of Toronto, Toronto, Ontario, Canada

${ }^{3}$ Division of General Internal Medicine, Department of Medicine, University of Toronto, Toronto, Ontario, Canada

\section{Correspondence to}

Dr Timothy Shun Him Kwok, timothysh.kwok@mail.utoronto. ca

Accepted 20 November 2018

\section{DESCRIPTION}

The prevalence of acupuncture use is increasing in the USA, as more patients seek out complementary medicine therapies in addition to conventional medicine. ${ }^{1}$ A specific form of acupuncture, known as Hari, involves the purposeful retention of acupuncture needles within a patient's subcutaneous tissue in order to alleviate chronic musculoskeletal pain. ${ }^{1}$ This may subsequently lead to alarming imaging findings.

A 94-year-old woman of Korean heritage with a new diagnosis of severe dementia was admitted to the general internal medicine service after an unwitnessed fall and urinary tract infection. The patient reported generalised pain, with difficulty relaying localisation. The paraspinal and hip girdle musculature were not particularly tender to palpation. To rule out acute fractures, radiographs of the chest, hip, thoracic and lumbar spine were obtained. These images demonstrated multiple filament-like

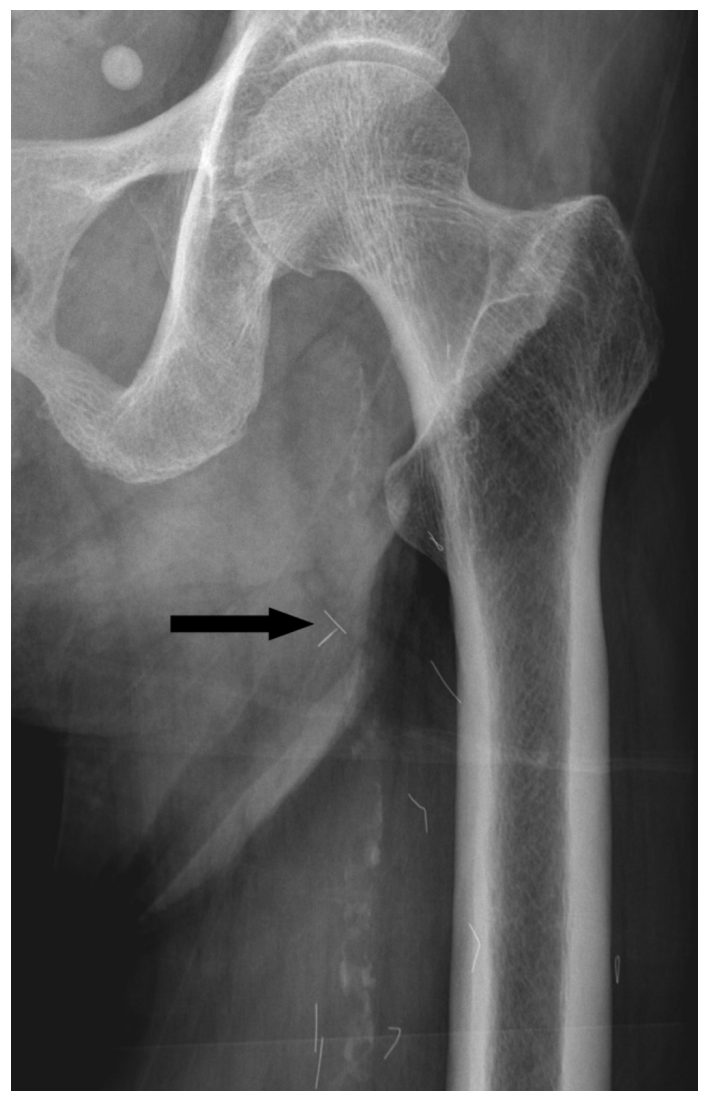

Figure 1 Coned down view of the left hip demonstrates 10 filament-like metallic densities (arrow) projecting over the proximal left thigh, many of which are bent, measuring up to $13 \mathrm{~mm}$ in length.

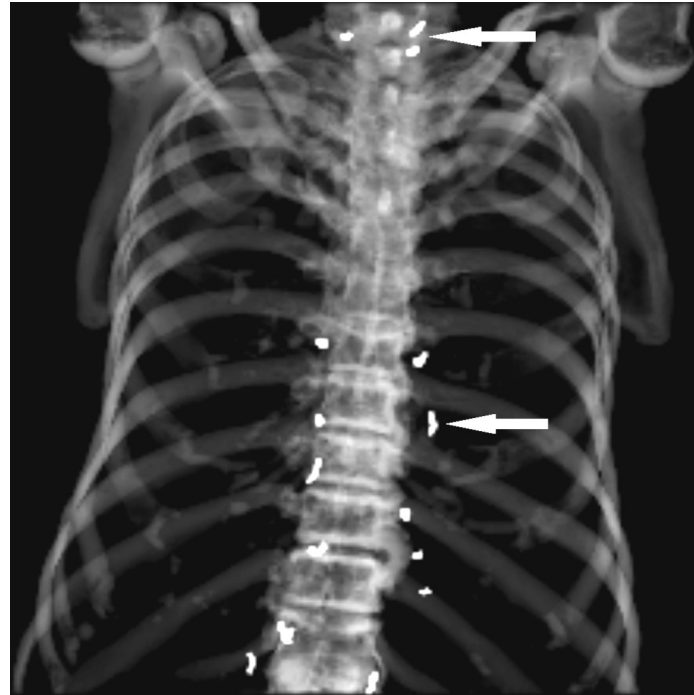

Figure 2 Three-dimensional volume rendering of a chest CT scan demonstrates 15 retained acupuncture needles (arrows) in the paraspinal musculature of the neck and mid-to-lower thoracic spine. Image prepared by Behruz Karasfi MRT. MRT, Medical Radiation Technologist.

densities projecting over the paraspinal musculature and proximal legs (figure 1). To clarify the nature of this abnormality, a CT scan of the thorax was ordered, confirming multiple retained acupuncture needles in the paraspinal musculature (figure 2). On further focused history with the patient and caregivers, it was noted that the patient had a single visit to a traditional Korean Hari acupuncturist in Toronto 30 years prior, where gold needles were placed along her back and hip girdle to alleviate musculoskeletal pain. The needles were intended to be permanent. The patient was ultimately treated for her urinary tract infection. Following a family meeting, a decision was made to pursue comfort care in the event of another acute medical illness.

Hari is an uncommon acupuncture technique originating from Japan. It is primarily practised in Korea and Japan, but its use has migrated to Asian communities in continental North America. Hari involves the permanent placement of needles into large muscle groups in an attempt to provide continual pain relief. ${ }^{2}$ Gold needles are predominantly used and represents financial wealth in Korean culture. ${ }^{2}$ However, this practice is considered rare compared with traditional forms of acupuncture, whereby the needles are subsequently removed. Retained acupuncture needles have been noted in the literature; however, clinical consequences of this phenomena are not well 
documented. ${ }^{1}$ Migration of the needles has been reported from the subcutaneous tissues to intra-abdominal organs. ${ }^{1}$ The prevalence of retained acupuncture needles is unknown. ${ }^{1}$

To our knowledge, this case details the longest latency of retained acupuncture needles before clinical or radiographical detection. Fortunately, the patient did not suffer any immediate adverse consequences, though was subjected to unnecessary investigations. While standard stainless steel acupuncture needles have the potential to cause significant imaging artefacts on MRI, they were not found to induce radiofrequency heating during MRI. Non-ferromagnetic needles (eg, gold) are MR compatible. ${ }^{3}$ Other metal alloys, including those with a strongly ferromagnetic composition, may have more malicious consequences when exposed to magnetic gradients. ${ }^{3}$ In clinical practice, added attention is needed in obtaining a full history for

\section{Learning points}

- Given the increasing prevalence of complementary medicine use, we highlight the importance of taking a full history to exclude retained metallic fragments.

- Although gold acupuncture needles are MR compatible, many preparations are of unknown metallic composition and may cause adverse effects during MRI. retained metallic fragments, especially considering the increasing prevalence of acupuncture use. Knowledge of the practice of Hari acupuncture and its associated imaging findings can prevent clinical confusion, avoid unnecessary imaging and ensure patient safety during clinical investigations.

Acknowledgements The authors wish to thank Behruz Karasfi for the preparation of the images.

Contributors TSHK contributed to the design and writing of the manuscript. MM contributed to the preparation of the images and descriptions. All authors contributed to the revisions and critical review of the manuscript. The final manuscript has been seen and approved by all the authors. The study has been given necessary attention to ensure the integrity of the work.

Funding The authors have not declared a specific grant for this research from any funding agency in the public, commercial or not-for-profit sectors.

Competing interests None declared.

Patient consent for publication Next of kin obtained.

Provenance and peer review Not commissioned; externally peer reviewed.

\section{REFERENCES}

1 Galbraith PJ, Richardson ML. Permanently retained acupuncture needles: radiographic findings and case report. Radiol Case Rep 2006;1:120-2.

2 Hollander JE, Dewitz A, Bowers S. Permanently imbedded subcutaneous acupuncture needles: radiographic appearance. Ann Emerg Med 1991;20:1025-6.

3 Mei L, Long X, Diao Y, et al. MRI evaluation of metal acupuncture needles. Acupunct Med 2013:31:404-8.

Copyright 2018 BMJ Publishing Group. All rights reserved. For permission to reuse any of this content visit

https://www.bmj.com/company/products-services/rights-and-licensing/permissions/

BMJ Case Report Fellows may re-use this article for personal use and teaching without any further permission.

Become a Fellow of BMJ Case Reports today and you can:

- Submit as many cases as you like

- Enjoy fast sympathetic peer review and rapid publication of accepted articles

- Access all the published articles

- Re-use any of the published material for personal use and teaching without further permission

For information on Institutional Fellowships contact consortiasales@bmjgroup.com

Visit casereports.bmj.com for more articles like this and to become a Fellow 